\title{
Characterization of physico-chemical properties of cervical mucus in relation to parity and conception rate in Murrah buffaloes
}

\author{
K. K. Verma ${ }^{1}$, Shiv Prasad $^{1}$, A. Kumaresan ${ }^{1}$, T. K. Mohanty ${ }^{1}$, S. S. Layek ${ }^{1}$, T. K. Patbandha ${ }^{2}$ and S. Chand ${ }^{1}$ \\ 1. Livestock Production Management Section, Livestock Research Center, National Dairy Research Institute, \\ Karnal, Haryana 132001, India; 2. Department of Livestock Production Management, Veterinary College, \\ Junagadh Agricultural University, Junagadh-362001, Gujarat, India \\ Corresponding author: K. K. Verma, Present address: Livestock Production Management Section, Indian Veterinary \\ Research Institute, Izatnagar - 243122, India, email: drkkvermavet@gmail.com \\ SP: shiv_kimothi@rediffmail.com, AK: ogkumaresan@gmail.com, TKM: mohanty.tushar@gmail.com, \\ SSL: drsslayek.vet@gmail.com,TKP: patbandhavet@gmail.com, SC: drsubhashndri@gmail.com \\ Received: 04-04-2014, Revised: 07-06-2014, Accepted: 09-06-2014, Published online: 07-07-2014
}

doi: 10.14202/vetworld.2014.467-471 How to cite this article: Verma KK, Prasad S, Kumaresan A, Mohanty TK, Layek SS, Patbandha TK and Chand S (2014) Characterization of physico-chemical properties of cervical mucus in relation to parity and conception rate in Murrah buffaloes, Veterinary World 7(7): 467-471.

\begin{abstract}
Aim: To characterize the physico-chemical properties of estrual cervical mucus among different parities and analyse their association with conception rate in Murrah buffaloes.

Materials and Methods: Cervical mucus was collected from the mid-cervix using sterile blue sheath before artificial insemination (AI) in Murrah buffaloes $(\mathrm{n}=94)$ and examined for appearance (transparent/ translucent), consistency (thin/ moderate/ thick), Spinnbarkeit value, arborisation pattern (typical/ atypical/ nil), $\mathrm{pH}$ and electrical conductivity. Artificial insemination was carried out using frozen-thawed semen by recto-vaginal method and pregnancy was confirmed by per-rectal examination after 60 days of insemination. Furthermore, the conception rates were calculated and their relationship with physico-chemical properties of cervical mucus was studied.

Results: Cervical mucus was clear and thin in $85.10 \%$ and $15.96 \%$ of estrus periods, respectively. Typical arborisation pattern of cervical mucus was observed in $54.25 \%$ of the estruses. The Mean $\pm \mathrm{SEM}$ of $\mathrm{pH}$, electrical conductivity and Spinnbarkeit value of mucus were $7.82 \pm 0.02,14.00 \pm 0.10 \mathrm{mS} / \mathrm{cm}$ and $14.18 \pm 0.59 \mathrm{~cm}$, respectively. Significantly $(\mathrm{P}<0.05)$ higher conception rate $(54.90 \%)$ was observed in buffaloes inseminated with typical arborisation pattern of cervical mucus as compared to atypical arborisation pattern $(20.00 \%)$ and no conception was recorded in the estruses with nil arborisation pattern.
\end{abstract}

Conclusion: The results of present investigation concluded that arborisation pattern has significant relationship with conception rate thus can be used as an important criteria to predict the right time of AI for improving conception rate in Murrah buffaloes.

Keywords: arborisation pattern, cervical mucus, conception rate, Murrah buffalo

\section{Introduction}

Cervical mucus is a viscoelastic secretion of constantly secreting mucus producing cells of the endo-cervix [1] and acts as a mechanical barrier to prevent intruding organisms. It is a complex biomaterial having a vital protective function in the cervix during pregnancy. Bovine cervical mucus exists into two phases, aqueous and gel [2]. The aqueous phase contains mostly water (92-95\%) with some ions and metabolites [3]; whereas the glycoproteins (mucins) are the major component of the gel phase [4]. Colour, appearance, $\mathrm{pH}$ and electrical conductivity along with other rheological properties like Spinnbarkeit value, flow elasticity, viscosity, thixotrophy, and arborisation pattern are the most important properties in relation to fertility. These properties vary with endocrinological status of reproductive cycle and directly associated with the estrogen: progesterone ratio and fertility status of dairy animals [5]. Basically

Copyright: The authors. This article is an open access article licensed under the terms of the Creative Commons Attribution License (http://creativecommons.org/licenses/by/2.0) which permits unrestricted use, distribution and reproduction in any medium, provided the work is properly cited. two types of cervical mucus are observed viz., estrogenic and gestagenic [6] which can be further divided into various subtypes.

The rheological properties of cervical mucus becomes more plentiful, watery and less viscous, during follicular phase, which facilitates the transport of spermatozoa in the female reproductive tract. However, it becomes opaque, thick, viscous and scanty during luteal phase not favourable to sperm migration [2]. Cervical secretion becomes more copious and watery during the estrogen dominating phase of ovarian cycle while the viscosity of mucus increases under high progesterone concentration. Therefore may be used in determining the stage of estrus for fixing an optimum time of insemination in farm animals. The occurrence of crystallization is common to all types of mucus. But degree of crystallization/ arborisation pattern in cervical mucus is under the control of two ovarian hormones $v i z$., estrogen and progesterone. The phenomenon of crystallization in cervical mucus progresses under the influence of estrogen where as progesterone diminishes the formation of arborisation pattern [3]. Thus it 
can be quite useful in predicting the onset of estrus, different stages of estrus and ovulation time in cattle and buffaloes [7].

Therefore, present investigation was aimed to study the physico-chemical properties of cervical mucus among different parities and analyse their association with conception rate in Murrah buffaloes.

\section{Materials and Methods}

Ethical approval: This study was approved by the Institutional Animal Ethics Committee framed for the research by the institute authority. Necessary measures were taken to curtail the pain or distress to animals.

Study area: The present study was conducted on Murrah buffaloes $(\mathrm{n}=94)$ maintained at Livestock Research Centre of National Dairy Research Institute, Karnal, Haryana for a period of 4 months (November 2011 - February 2012). The study place is located on $29^{\circ} 43^{\prime} \mathrm{N}$ latitude and $76^{\circ} 58^{\prime} \mathrm{E}$ longitudes at an altitude of 245 meters above the mean sea level in the bed of Indo- Gangetic alluvial plain. A subtropical climate prevails in the area. There are four major seasons in the year viz., winter (December to March), summer (April to June), rainy (July to September) and autumn (October and November).

Experimental design and management of animals: Buffalo heifers ( $\mathrm{n}=13$ ) with body weight (BW) not less than $347 \mathrm{~kg}(427 \pm 23)$ and age above 27 months (39.37 \pm 4.28$)$ as well as buffalo cows ( $\mathrm{n}=81,1-6$ parity) with BW $580 \pm 8.8 \mathrm{~kg}$ and age $80 \pm 2.84$ months, were used in the study. The experimental buffaloes were free from anatomical and reproductive disorders as well as from other diseases. For easy identification, buffaloes were tagged with numbered plastic ear tags. The buffaloes utilized in this study were maintained under loose housing system, fed ad lib with seasonal green fodder along with additional concentrate at the rate of $1.0 \mathrm{~kg}$ for every $2.0 \mathrm{~kg}$ milk yield as followed by institute herd management practice.

Estrus detection and insemination: Murrah buffaloes were detected in estrus using teaser bull (BW $600 \mathrm{~kg}$ and age 5 years), visual observation of cardinal signs of estrus along with heat expectancy chart. Bull parading was carried out four times in a day, i.e. at morning (6.00 $\mathrm{am})$, forenoon $(10.00 \mathrm{am})$, afternoon $(2.00 \mathrm{pm})$ and at evening $(6.00 \mathrm{pm}), 30$ minutes in each shed. Experimental buffaloes in estrus were confirmed by per-rectal examination and AI was practiced by recto-vaginal method using good quality frozen-thawed semen from a bull of known fertility.

Collection of cervical mucus: Cervical mucus was collected on the day of estrus prior to the AI using sterile blue sheath (IMV Technologies France, France). The sterile sheath was fitted in a "Universal artificial insemination gun" and mucus was aspirated from the mid cervix by recto-vaginal method. Mucus samples were collected in a sterile tube $(5 \mathrm{ml})$ to study its physico-chemical characteristics.

Measurement of physico-chemical properties: Cervical mucus samples were collected in a sterile tube before AI and immediately taken to the laboratory for the examination of following characteristics:

Appearance: Appearance of cervical mucus was judged using direct visual observation and categorised into clear/transparent and cloudy/translucent.

Consistency: A few drops of mucus sample were placed into a grease free glass slide and slide was inclined to $45^{\circ}$ for the detection of consistency of the mucus. By observing the movement, the mucus sample was categorised into three different consistencies i.e. thin, moderate and thick.

Spinnbarkeit value: For measuring the Spinnbarkeit value, 2-3 drops of collected mucus sample were taken on a grease free glass slide; then another grease free glass slide was placed over it. The mucus was stretched between two slides by moving the second slide away from first one, until the mucus breaks. The distance between the two slides just before the breakage of the mucus string was measured through a scale (cm scale) mounted on the wall, known as Spinnbarkeit value. In this study Spinnbarkeit values were categorized into three groups 0-8 cm, 8-16 cm and $16-24 \mathrm{~cm}$.

Arborisation pattern: Two to three drops of well mixed cervical mucus spread uniformly over a grease free glass slide and air dried. The air dried slide was examined under microscope using low power objective (10X) for crystallization pattern of the mucus, known as arborisation pattern. The arborisation pattern of the observed mucus was grouped into three classes viz., typical, atypical and nil.

pH: $\mathrm{pH}$ of cervical mucus was measured using $\mathrm{pH}-$ Conductivity Benchtop (Orion 4 star, Thermo Electron Corporation, USA) and observed $\mathrm{pH}$ were categorised into three groups i.e. 7.0-7.5, 7.5-8.0 and $>8.0$.

Electrical conductivity: Before measuring the electrical conductivity (EC), mucus samples were first vortexed in a vortex mixture (Spinix Corporation, $C A$, USA) until it got lysed and became a free flowing liquid. Then electrical conductivity was measured in the lysed cervical mucus using a pH-Conductivity Benchtop (Orion 4 star, Thermo Electron Corporation, USA) in mili-Siemens/cm unit $(\mathrm{mS} / \mathrm{cm})$ and divided into three groups $9-13.5 \mathrm{mS} / \mathrm{cm}, 13.5-15 \mathrm{mS} / \mathrm{cm}$ and $>15 \mathrm{mS} / \mathrm{cm}$.

Conception rate: Pregnancy was confirmed by rectal palpation after 60 days of AI in non returned buffaloes and conception rate was calculated by using following formula:

Conception rate $(\%)=$ Number of pregnant animals $/$ Total number of animals inseminated X 100

Statistical analysis: In this study descriptive statistics were calculated for average Spinnbarkeit value, $\mathrm{pH}$, and electrical conductivity and presented in Mean \pm SEM format. The chi square analysis was used to compare the physico-chemical properties of cervical 

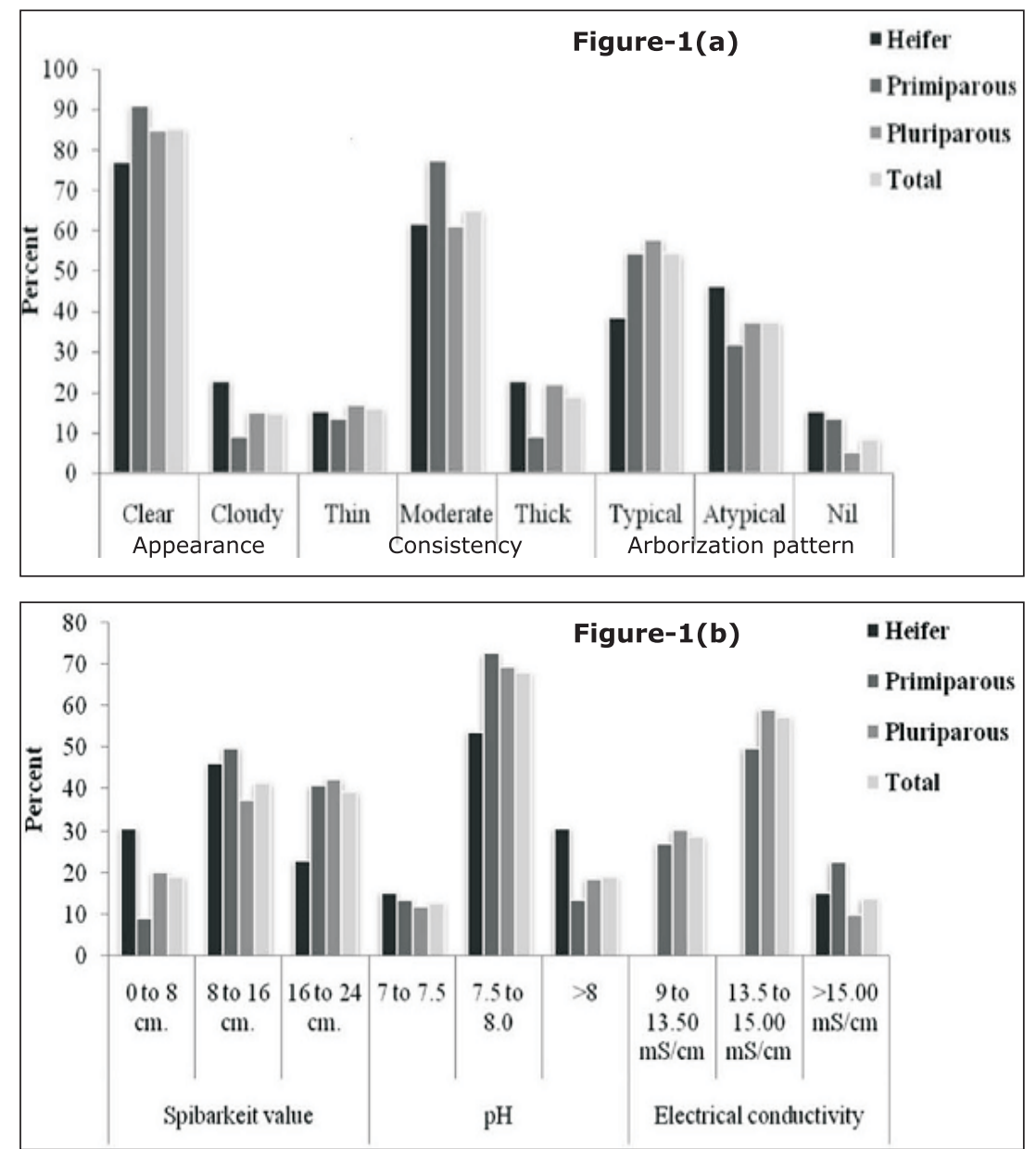

Figure-1(a \& b): Physico-chemical chemical properties of cervical mucus in Murrah buffaloes $(n=94)$ at the time of AI.

mucus among different parity of Murrah buffaloes and their relationship with conception rate. Statistical analysis was performed using Sigma Plot $11^{\circledR}$ software (Systat software Inc. USA).

\section{Results and Discussion}

In dairy animals the appearance of estrual cervical mucus changes during different phases of the estrus i.e., clear/ transparent mucus at early stage, which gradually changes to turbid at mid-estrus and translucent at the end of estrus [8]. Clear mucus discharge was observed in $90.90 \%$ of primiparous buffaloes, $84.75 \%$ of pluriparous and $76.92 \%$ of heifers (Figure-1a) but the difference was statistically non significant. Majority of buffaloes $(85.10 \%)$ had clean/ transparent mucus which might be due to early stage of estrus and better reproductive health. Our findings are in agreement with Gill et al. [8]. Moderate consistency of cervical mucus was observed in $64.68 \%$ of buffaloes, which may be because of early to mid phase of estrus. Findings of this study are almost similar to Gunasekaran et al. [9].

Cervical mucus in $54.25 \%$ buffaloes (Figure-1a) had shown typical arborisation pattern with primary, secondary and tertiary venation (Figure-2a) while remaining $37.24 \%$ and $8.51 \%$ buffaloes had atypical (Figure-2b) and nil arborisation patterns respectively.

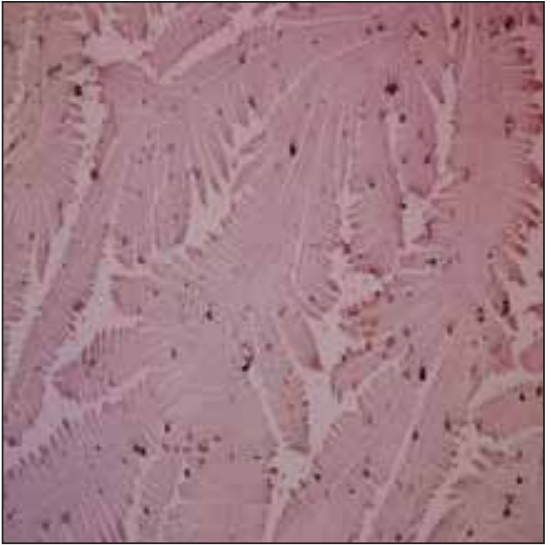

Figure-2a

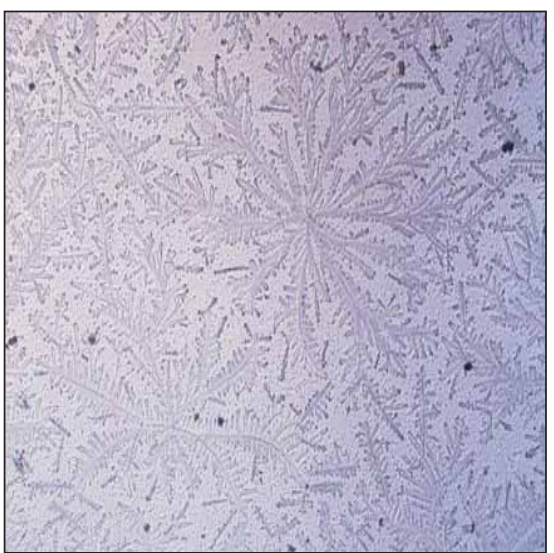

Figure-2b

Figure-2: Typical (a) and atypical (b) arborisation pattern of cervical mucus in 94 Murrah buffaloes during estrus.
In this study typical fern pattern in cervical mucus was found in $54.25 \%$ estruses which might be due to increased peripheral estrogen concentration at the time of estrus indicating right time of insemination. Almost similar values were observed by Rangnekar et al. [5]. The Spinnbarkeit reduces under the influence of progesterone and increases with high level of estrogen and reaches at peak during ovulatory phase. The Spinnbarkeit value of cervical mucus (Figure-1b) in $46.15 \%$ heifers and $50.00 \%$ primiparous cows was 8 to $16 \mathrm{~cm}$, whereas $42.37 \%$ of pluriparous buffaloes were found in the range of 16 to $24 \mathrm{~cm}$. The average value of Spinnbarkeit in this study was $14.16 \pm 0.60 \mathrm{~cm}$ which is in accordance with Rangnekar et al. [5].

Cervical mucus of $68.09 \%$ estruses were within $\mathrm{pH}$ range of $7.5-8.0$ while $19.15 \%$ and $12.76 \%$ cervical mucus were in $\mathrm{pH}$ range of $>8$ and 7.0-7.5 respectively (Figure-1b). Majority of primiparous buffaloes (72.73 $\%$ ) had cervical mucus in alkaline range during insemination, which may be because of increased mucoproteins, sodium chloride and water content of cervical mucus due to higher estrogen level during the peri-estrus. Our findings (average $\mathrm{pH}$ value $7.83 \pm 0.02$, range 7.2 - 8.4) are in accordance with Rangnekar et al. [5] where as Gunasekaran et al. [10] reported lower values in crossbred cows. Cervical mucus in $57.45 \%$ of estruses was in the electrical conductivity range 13.50-15.00 
Table-1: Conception rate in various classes of cervical mucus in Murrah buffaloes $(n=94)$ during periestrual period

\begin{tabular}{|c|c|c|c|c|}
\hline \multicolumn{2}{|c|}{ Cervical mucus characteristics } & \multirow{2}{*}{$\begin{array}{c}\text { Total no. of animals } \\
80\end{array}$} & \multirow{2}{*}{$\begin{array}{c}\text { No. of pregnant animals } \\
33\end{array}$} & \multirow{2}{*}{$\frac{\text { Conception rate (\%) }}{41.25}$} \\
\hline Appearance & Clear & & & \\
\hline & Cloudy & 14 & 2 & 14.28 \\
\hline \multirow[t]{3}{*}{ Consistency } & Thin & 15 & 4 & 26.66 \\
\hline & Moderate & 61 & 29 & 47.54 \\
\hline & Thick & 18 & 2 & 11.11 \\
\hline \multirow[t]{3}{*}{ Arborisation pattern } & Typical & 51 & 28 & $54.90^{*}$ \\
\hline & Atypical & 35 & 7 & 20.00 \\
\hline & Nil & 8 & 0 & 00.00 \\
\hline \multirow[t]{3}{*}{ Spinnbarkeit value $(\mathrm{cm})$} & $0-8$ & 18 & 3 & 16.66 \\
\hline & $8-16$ & 39 & 14 & 35.89 \\
\hline & $16-24$ & 37 & 18 & 48.64 \\
\hline \multirow[t]{3}{*}{$\mathrm{pH}$} & $7-7.5$ & 12 & 3 & 25.00 \\
\hline & $7.5-8.0$ & 64 & 27 & 42.18 \\
\hline & $>8$ & 18 & 5 & 27.77 \\
\hline \multirow[t]{3}{*}{ Conductivity (mS/cm) } & $9-13.5$ & 27 & 5 & 18.51 \\
\hline & $13.5-15.00$ & 54 & 23 & 42.59 \\
\hline & $>15.00$ & 13 & 7 & 53.84 \\
\hline
\end{tabular}

$\mathrm{mS} / \mathrm{cm}$, while remainder $(28.72 \%$ and $13.83 \%)$ were within the range $9-13.5 \mathrm{mS} / \mathrm{cm}$ and $>15.00 \mathrm{mS} / \mathrm{cm}$, respectively (Figure-1b). We found large number of buffaloes with greater range of electrical conductivity which might be due to increased electrolyte concentrations in mucus during estrus. The average conductivity in this study (13.97 $\pm 0.10 \mathrm{mS} / \mathrm{cm}$, range $9.23-15.86)$ is in agreement with Sopelink [11].

Visual appearance of cervical mucus is a good indicator of reproductive health status of animals [3]. Clean and transparent cervical mucus shows normal health while reproductive disorders may results turbid and dirty mucus. We observed $41.25 \%$ conception rate in clear and transparent cervical mucus (Table-1) at the time of insemination may be because of enhanced sperm penetration, proper stage of estrus and better reproductive health status. Our results are in accordance with Mufti et al. [12]. Findings of this study had shown $47.54 \%$ conception rate in estruses with thin to moderate consistency of cervical mucus (Table-1) which might be due to enhanced migration of spermatozoa in female reproductive tract. Intertwined muco-proteins and impaired penetration and progressive movement of spermatozoa may be the probable cause of lower conception rate in thick cervical mucus. Our results are supported by Layek et al. [13] and Rangnekar et al. [5], while higher values were observed by Kumar et al. [14].

In this study, significantly $(\mathrm{P}<0.05)$ higher conception rate $(54.90 \%)$ (Table-1) was observed in buffaloes inseminated with typical arborisation pattern in their cervical mucus as compared to atypical pattern (20\%). Greater conception rate in typical arborisation pattern may be because of facilitated movement of spermatozoa as compared to nil or dotted type arborisation pattern [7]. Our results are in agreement with Kumaresan et al. [15] and Layek et al. [13]. We found 48.64\% conception rate in buffaloes inseminated with cervical mucus having high Spinnbarkeit value $(16-24 \mathrm{~cm})$ might be due to proper stage of estrus because Spinnbarkeit value attains its peak immediately before or during the ovulatory phase under the influence of estrogen, and decreases subsequently as the level of progesterone increases during luteal phase in cows. Our findings are supported by Modi et al. [16].

In the present study, estruses with moderately alkaline (7.5-8.0) mucus (Table-1), had shown 42.18\% conception rate. This may be because of improved progressive motility of spermatozoa and suitable uterine environment for embryo [5]. Our results are in agreement with Modi et al. [16]. Buffaloes inseminated with greater range $(>15 \mathrm{mS} / \mathrm{cm})$ of electrical conductivity (Table-1) showed $53.84 \%$ conception rate, which may be because of facilitated activation of spermatozoa and uterine motility, that enhance the process of fertilization. Our results had shown a positive correlation between conception rate and EC of cervical mucus which is in accordance with Layek et al. [13].

\section{Conclusion}

From the findings of this study, it can be concluded that various physico-chemical properties of cervical mucus did not vary with parity while the arborisation pattern has significant relation with conception rate. Therefore, it can be used as a tool to decide the right time for insemination in Murrah buffaloes.

\section{Authors' contributions}

KKV, SP and TKM designed the study. KKV conducted the study and analyzed the data. TKP and SC contributed in sample collection. AK and SSL drafted and revised the manuscript. All authors read and approved the final manuscript.

\section{Acknowledgements}

The authors express their sincere sense of gratitude to Director and Vice Chancellor, National Dairy Research Institute, Karnal, for providing all research facilities. The work was funded by the World Bank supported NAIP project (NAIP/C4/C2008). The first author is thankful to Indian council of Agricultural Research, India for providing Junior Research Fellowship.

\section{Competing interests}

The authors declare that they have no competing interests. 


\section{References}

1. Glover, F. A. (1960) The effect of ovarian hormone administration on the consistenc of cervical secretion in the cow. J. Reprod. Fertil., 1: 110-111.

2. Rutllant, J., López-Béjar, M. and López-Gatius, F. (2005) Ultrastructural and rheological properties of bovine vaginal fluid and its relation to sperm motility and fertilization: A review. Reprod. Domest. Anim., 40: 79-86.

3. Tsiligianni, T., Karagiannidis, A., Brikas, P. and Saratsis, P. (2001) Physical properties of bovine cervical mucus during normal and induced (progesterone and/or PGF2 $\alpha$ ) estrus. Theriogenology, 55: 629-640.

4. Pluta, K., Irwin, J. A., Dolphin, C., Richardson, L., Fitzpatrick, E., Gallagher, M. E., Reid, C. J., Crowe, M. A., Roche, J. F., Lonergan, P., Carrington, S. D. and Evans. A. C. (2011) Glycoproteins and glycosidases of the cervix during the periestrous period in cattle. J. Anim. Sci., 89(12): 403242.

5. Rangnekar, M. N., Dhoble, R. L., Gacche, M. G., Ingawale, M. V., Sawale, A. G. and Jadhav, J. M. (2002) Physical properties of oestrual cervical mucus in repeat breeding crossbred (Holstein Friesian) cows with reference to fertility. Indian J. Anim. Sci., 72(12): 1122-1124.

6. Vigil, P., Cortes, M. E., Zuniga, A., Riquelme, J. and Ceric, F. (2009) Scanning electron and light microscopy study of the cervical mucus in women with polycystic ovary syndrome. $J$. Electron Microsc., 58:21-27.

7. Alena, J., Ludek, S., Mojmir, V. and Franstisek, L. (2008) Factors affecting the cervical mucus crystallization, the sperm survival in cervical mucus, and pregnancy rate in Holstein cows. J. Cent. Eur. Agric., 9(2): 377-384.

8. Gill, R. S., Gangwar, P. C. and Kooner, D. S. (1974)
Optimum time of insemination for high conception rate in buffaloes. Indian J. Anim. Sci., 43: 355-357.

9. Gunasekaran, M., Singh, C. and Gupta, A. K. (2007) Effect of oestrus behaviour on fertility in Murrah buffaloes. Indian J. Dairy Sci., 60(5): 348-351.

10. Gunasekaran, M., Singh, C. and Gupta, A. K. (2008) Effect of estrus behaviour on fertility in crossbred cattle. Indian Vet. J., 85: 159-163.

11. Sopelink, P. (1971) Variation in the milk production, activity rate and electrical impedence of cervical mucus over the oestrus period of dairy cows. Afri. J. Reprod. Sci., 24(5): 231248.

12. Mufti, M. M. R., Alam, M. K., Sarker, M. S., Bostami, A. B. M. R. and Das, N. G. (2010) Study on factors affecting the conception rate in red chittagong cows. Bangladesh J Anim Sci., 39 (1\&2): $52-57$.

13. Layek, S.S., Mohanty, T.K., Kumaresan, A., Behera, K. and Chand, S. (2013) Cervical mucus characteristics and periestrual hormone concentration in relation to ovulation time in Zebu (Sahiwal) cattle. Livest. Sci., 152(2-3): 273281.

14. Kumar, R., Kumar, D. and Roy, B. (2011) Studies on repeat breeding of buffaloes. Buffalo Bull., 30(3): 177-187.

15. Kumaresan, A., Prabhakaran, P. P., Bujarbaruah K. M., Pathak, Bijoy Chhetri K. A. and Ahmed, S. K. (2009) Reproductive performance of crossbred dairy cows reared under traditional low input production system in the eastern Himalayas. Trop. Anim. Health Prod., 41(1): 71-78.

16. Modi, L. C., Suthar, B. N., Nakhashi, H. C., Sharma, V. K. and Panchasara, H. H. (2011) Physical Characteristics of Estrual Cervical Mucus and conception rate in Repeat Breeder Kankrej Cattle. Int. J. Agro Vet. Med. Sci. 5(4): 416-423. 